\title{
I'm gonna get it for my birthday: Young children's interpretive reproduction of literacy practices in school
}

\author{
Lucy Henning
}

\begin{abstract}
In this paper I argue that the mainstream assumptions that inform current educational policy and practice for young children's in-school literacy development in schools are insufficient to secure a helpful account of young children's classroom literacy practices. The particular problem lies with the reliance of such policy and practice on perspectives that assume firstly that literacy acquisition comprises the orderly acquisition of predefined concepts, skills and knowledge; and secondly that the task of schools is to bring individual children's concepts, skills and knowledge of literacy in line with what is considered 'normal' for their age. I argue that such perspectives are too narrow to secure a clear enough view of the complex phenomena of young children's encounter with being taught to read and write in school. In this paper I present two alternative theoretical lenses through which the familiar phenomena of young children's encounter with being schooled in literacy can be viewed: firstly that of Literacy as a Social Practice (hereafter LSP) (Street 1984; Barton and Hamilton1998, Barton 2007) and secondly that of 'interpretive reproduction', a theoretical account of young children's participation in their social worlds developed by William Corsaro (cf Corsaro 2000, 2005, 2011, 2015). To demonstrate how helpful such perspectives can be in understanding the familiar phenomena of young children's literacy schooling, I apply them to the analysis of one child, Dean's, encounter with schooled literacy within the social world of an early twenty-first century West London Classroom.
\end{abstract}




\section{Introduction}

For the past thirty years in the UK the aspirations of education policies connected with young children's literacy acquisition have been to ensure that all children of primary school age ( $3-11$ years) attain a defined set of literacy skills and knowledge. Whilst such polices have prompted changes in educational practices intended to support the achievement of such aspirations, they have been consistently driven by the same assumptions about the relationship between young children, schooling and literacy, in particular that: a) literacy is comprised of a set of skills and knowledge that can be applied in any context where engagement with texts is required; b) young children require the close supervision of adults to ensure they acquire such skills and knowledge; c) that individual children progress at different rates along a universal path to literacy; d) that this progress can be measured against the chronological age at which each child is able to demonstrate such skills and knowledge in their reading and production of printed texts. For example, in current English education policy children can be categorised as working at, below, or above expected age-related standards for the acquisition of literacy skills and knowledge. Assessment of their membership of such categories is made through a system of national assessments against standardised benchmarks at the ages of 5,7 and 11 years (see for example STA 2015). The outcomes of these tests form part of OFSTED (the UK Office for Standards in Education) evaluations of the effectiveness of individual schools and education polices for securing children's progression in literacy.

However, despite considerable expenditure on far-reaching educational reforms the problem of 'underachievement' in literacy and education in general persists, particularly for children classed as 'disadvantaged' (cf House of Commons 2005; Gove, 2010; Andrews, Robinson and Hutchinson 2017). In England, this is seen as policy priority, particularly in terms of the effect the 'attainment gap' between the 'highest' and 'lowest achievers' in the English education system has on England's ranking in international surveys of educational attainment such as PIRLS (Progress in International Reading Literacy Study (cf McGrane et al 2017)) and PISA (Programme for International Student Assessment (cf OECD 2016)). A priority for policy makers is to improve the UK's performance in such surveys, which are used to measure the success or otherwise of UK schools (cf DoE 2010, Gibb 2017) I argue that the assumptions that drive such reforms do not allow enough scope for understanding young children's in-school literacy practices. For example, policy reform often relies on 'best practice' research which focuses on adult activity in 
securing individual children's progress towards, and attainment of, defined and measurable literacy skills (Rose 2006, OFSTED 2010, Gibb 2017). Young children are assumed to make differential rates of progression depending firstly on how far they match adult expectations of their literate behaviour; and secondly on the presumed effectiveness of adult interventions designed to secure this expected behaviour. For example, the UK government minister for schools attributed a recent improvement in the UK's PIRLs reading scores to adult implementations of phonics pedagogy for the teaching of reading, a long-standing government priority (Gibb 2017). I suggest that whilst such improvements are welcome, the effect of particular pedagogical approaches can only be partially understood without greater emphasis on the work of the human agents who act upon them. Whilst such actions are often researched in terms of adults' work (cf Ball 1993, Papen 2016), I argue that there is a need for greater emphasis on the children's activity - whether that activity matches adult expectations or otherwise. I suggest that important areas for research are firstly what young children do when required to engage with schooled literacy tasks; secondly what engaging with schooled literacy tasks means to those young children, both collectively and individually; and thirdly the relationship between those meanings and what the children do when tackling literacy tasks set by their teachers.

Research that emphasises these aspects of young children's engagement with schooled literacy tasks involves an emphasis on 'practice' and 'meaning' rather than 'progress' and 'attainment'. For example, Anne Haas Dyson discusses similar curriculum regulation and testing in US schools to that described above (see for example Dyson 2001, 2006, 2010). Dyson argues that linear mapping of children's literacy development through '... orderly lists of literacy knowledge and know-how' (Dyson 2001 p.10) is not enough to understand children's active engagement in practising literacy (Dyson 1999, 2001, 2006, 2010). Her influential work emphasises how:

'...children's engagement in the complex communicative act of writing is energised and organised by their agency and their desire to participate in a world shared with others.'

[Dyson 2010 p.26]

Research adopting perspectives that allow for such 'active agency' allow for new insights to be generated into the familiar phenomena of young children being taught to read and write in school. Two such perspectives that I have found helpful for my 
theoretical work are those of Literacy as a Social Practice (Street 1984, Barton and Hamilton 1998); and 'interpretive reproduction' (Corsaro 2005, 2015). In this paper I shall draw on these perspectives to analyse one child - Dean's - participation in a schooled literacy lesson. This analysis demonstrates that young children's in-school literacy practices are more complex than currently imagined in English Education policy. I suggest that more research is needed into such practices if more helpful ways are to be found of supporting young children's in-school literacy development.

\section{Literacy as a Social Practice}

A key feature of an LSP approach to studying literacy is its concern with how people practice literacy when required to engage with texts in their everyday lives. Barton and Hamilton (2000) offer a useful definition of what is meant by a literacy practice:

\footnotetext{
'...practices are not observable units of behaviour since they also involve values, attitudes, feelings and social relationships. This includes people's awareness of literacy, constructions of literacy and discourses of literacy, how people talk about and make sense of literacy.'
}

[Barton and Hamilton 2000 p.7]

From this perspective it is important to understand what practising literacy in the classroom means to young children. The practices of literacy the children produce in school will be contingent upon their interpretations of their current social context that is - the classroom. This means that children's in-school literacy practices cannot be studied as an autonomous thing, separate from the social world of the classroom (Street, 1984 p.8). LSP researchers have identified a literacy dominant in schooling, sometimes referred to as 'schooled literacy,' which is understood as specific to that particular institutional setting, (Street and Street 1995; Barton, Hamilton and Ivanic 2000; Gregory and Williams 2000; Barton 2007; Papen 2016). The dominance of this schooled literacy in classrooms means that all practitioners in the classroom whether adults or children - will be aware of it as a feature of the social context of schooling and will account for it in their own classroom practices of literacy. However, this accounting for schooled literacy does not necessarily mean that all practitioners will share the same values attitudes and beliefs about what they are doing as they practice literacy in school. The work of LSP researchers Jill Bourne and Janet Maybin demonstrates that whilst schooled literacy assumes dominance over others in the social context of the classroom, alternative practices may occupy the same social space but are assigned less value (Bourne 2001, 2002; Maybin 2007, 2013). 
For example, Maybin (2013) describes 11-12 year-old children engaging in 'unofficial' literacy activities in an English Primary School. As the teacher worked to prepare the children for 'official' assessment activities through the discussion of a poem, the children pursued 'unofficial' literacy activities, '....revisioning, reproducing and playing with particular lines...' in the poem (Maybin 2013 p.9) Maybin argues that such 'unofficial' activities offer evidence of the skills expected in official standardised tests, but the fleeting, fragmentary nature of such activities meant they were not included in 'official' assessments of the children's literacy capabilities.

Such accounts of a diversity of literacy practices within the social space of the classroom opens up the possibility that firstly young children cannot be assumed to be sharing adult values, attitudes and beliefs about school-assigned literacy tasks; and secondly, that those children may take a particular stance in relation to schooled literacy as they engage in such tasks. From an LSP perspective, these interpretive aspects of young children's classroom participation are key to understanding why young children do what they do when practising literacy in classrooms. However, schooled assessments of young children's literacy development focus solely on the extent to which they comply with adult expectations, particularly in terms of their acquisition and application of literacy skills. This means that adults working only within the discourses and practices of schooled literacy may not be adequately equipped to understand young children's active and interpretive work to engage with tasks intended to support their literacy acquisition. This raises the possibility that those concerned with young children's literacy acquisition do not have enough information to make fully considered decisions about appropriate pedagogical interventions.

The shift of emphasis from schooled concerns with 'learning' and 'progress' to concentrate on 'practice' and 'meaning' presents a problem for LSP researchers working within schooled contexts. Notions of individual cognitive 'learning', 'development' and 'progress' are central to the ways in which modern education systems construct the child (cf Walkerdine 1993; Hendrick 1997; Wyness 2012). This means that researchers adopting an LSP approach into understanding young children's in-school literacy practices are not just adopting an alternative perspective on literacy to that dominant in schooling, but also need to engage in a critical and reflexive account of perspectives on young children (cf Gregory, Long and Volk 2004). I argue that William Corsaro's conceptualisation of children's action in the 
social world as involving processes of 'interpretive reproduction' (Corsaro 2000, $2005,2011,2015)$ offers a way of making that shift.

Corsaro's work challenges dominant schooled perspectives on children by positioning them as full participants in the social world, actively contributing to cultural production and change (Corsaro 2000, 2015). What is particularly significant for studying young children's in-school literacy practices is the emphasis on young children's peer cultures. Corsaro describes how '....in attempting to make sense of the adult world, children come to collectively produce their own peer worlds and cultures.' (Corsaro 2015 p.23). The widespread schooled practice of organising children into similar-age classes offers ample opportunities for such peer cultures to flourish. When children engage in processes of 'interpretive reproduction' they collectively reproduce cultural routines in response to their interpretations of the social world (Corsaro and Molinari 2000). I suggest that literacy practices can be seen as such cultural routines. From this perspective then, children in school do not simply adopt the literacy practices taught by adults, as assumed in the dominant discourses of schooled literacy, but interpretively reproduce literacy practices that are tailored to their collective, as well as individual, interests and priorities (cf for example Dyson 1987; Corsaro and Nelson 2003). I return to Corsaro's work later in the paper when I begin my analysis of Dean's literacy practices.

\section{Outline of the research}

Adopting perspectives which emphasise active human agency and the importance of social context means that taking an ethnographic approach to research is particularly apt for studying young children's classroom literacy practices (cf Hammersley and Atkinson 2007). This paper draws on a PhD study which applied ethnographic principles to the collection and analysis of data in order to address the question 'What do young children do when they encounter schooled literacy?' Flewitt (2011) offers a summary of ethnographic principles that demonstrate how these can support research into young children's encounter with schooled literacy:

'...over-arching characteristics of ethnographic research include recognition that: 1) data should be drawn from 'real world' contexts; 2) both participant (emic) and researcher (etic) perspectives should be valued; and 3) meanings emerge in social and cultural contexts from the interwovenness of language, bodily movements, artefacts, images and technologies.

[Flewitt 2011] 
In accordance with such an approach, a range of data was collected over time, enabling a detailed picture of the children's literacy practices to be built up from a range of sources. Data collection was carried out over thirty one-morning-a-week visits to the 'real world' context of Amber Class, a Year 1 (5 - 6 years old) class in Oakwood Primary School in London. The school was described by OFSTED in 2009 as larger than average with three times the national average of pupils from minority ethnic backgrounds, half the pupils speaking a language in addition to English and twice the national average of pupils entitled to free school meals, a key indicator of 'social disadvantage'.

The aim of the study was to understand how children practised literacy in mainstream literacy lessons which were shaped by the discourses and practices of schooled literacy outlined above. It was key that participant perspectives - those of the children - remained at the centre of the research. For this reason, I collected as much data as I could in order to attempt to capture the meanings that emerged for the children in the social and cultural context of schooling (Flewitt 2011, above). The data set contains almost 7 hours of video recordings and some 16 hours of audio recordings which comprise both classroom observations and interviews with the children. This digital data is accompanied by field notes, 588 photographs, copies of the children's written work as well as digital documents including the teachers' planning for literacy lessons. Ethical guidelines from Kings College, London were followed and permission was sought from all research participants, with parents consenting on behalf of their children. Over the year I worked to ensure the children were aware of my purpose in their classroom and that of the recording devices that I used. As they became familiar with me, they were usually willing to talk about their literacy practices, both 'in the moment' and in interviews; however their wishes were respected when they did not wish to participate in the research.

My previous teaching and teacher-training experience meant that, as well as carrying out data collection, I often took groups for teaching in Amber and other Year 1 classes as a condition of my access to the school. This professional aspect of my participation in the research setting meant that reflexivity was important throughout the research process, particularly in differentiating between the assumptions I drew on when teaching and those which informed my research aims. Detailed fieldnotes made throughout each visit to the school supported this work (cf Blommaert and Jie 2010 p.37). The use of digital recording devices supported uncovering the presence 
of unofficial discourses and practices in schooled literacy lessons (Maybin 2007, 2013 Bourne 2001, 2002) particularly those that were not dependent on what the teacher said or did. The use of the video camera also enabled me to capture the multi-modal nature of literacy practices (Jewitt 2012) including non-verbal aspects of communication and the ways in which the children took up resources that were available to them.

My data analysis began with making rough transcriptions of the digital data. This involved placing the data in the context of other data sources that had relevance to it before working carefully through each recording. Once I had identified key episodes from the data, I adopted a micro-analytic approach (cf Rampton 2007) in a momentby-moment analysis of the children's literacy practices as they unfolded, with the aim of placing the children at the centre of detailed reconstructions of these episodes (Rampton 2006). I engaged in a process of 'constant comparison' (Heath and Street 2008), whereby I reviewed and refined my interpretations of the data collected against a reading of existing studies. In the course of this process of analysis, Corsaro's work on 'interpretive reproduction' (Corsaro 2011, 2015) emerged as the most plausible way of understanding the children's work to reproduce in-class literacy practices.

It is important to note two factors concerning the scope of the research. Firstly, the research was not directly concerned with the intersections between factors such as the children's gender, social class, ethnicity or language backgrounds and their literacy practices. Although such factors would certainly play a part in the children's reproduction of literacy practices (see for example Heath 1983; Gregory and Williams 2000; Gregory Long and Volk 2004; Bourne 2002; Maybin 2007), it is beyond the scope of this project to consider such factors in detail. Furthermore, the research focus was the children's practices rather than the teacher's pedagogical work and this emphasis contributed to the teacher's generous participation in the study. For this reason it would be unfair to speculate on any aspect of the teacher's practice. It should be noted however that the teacher maintained positive relations with her class and their families throughout the school year.

The names of the children and adults in the study are pseudonyms and cannot be used to inform assumptions about the children's characteristics. No one child was the focus of the original study, however for the purposes of this article I draw chiefly on data relating to Dean and his engagement with a literacy lesson in February, about 
half way through the school year. I begin by describing the schooled expectations for Dean and his classmates' participation in the lesson, as these reflect the assumptions made about young children and their in-school literacy practices described in the introduction to this paper. Following this, I introduce Dean before drawing on evidence of his literacy practices to outline Corsaro's theory of 'interpretive reproduction' in more detail. This conceptualisation of young children as actively engaged in cultural reproduction in the social world aligns with that of LSP. It supports my continued analysis of Dean's writing processes in terms of his interpretive reproduction of literacy practices.

\section{Schooled assumptions about young children's in-school literacy practices}

I begin by describing the schooled expectations for Amber Class' children's including Dean's - participation in a writing lesson carried out in February. The task set was for each child to describe the favourite toy that they possessed. The schooled expectations for this writing task set were framed by notions of 'normal' literacy development related to the children's chronological ages and enacted through professional practices that assumed particular attributes for young children.

Below (Fig. 1) is a photograph of the text the teacher produced with children to demonstrate these expectations:

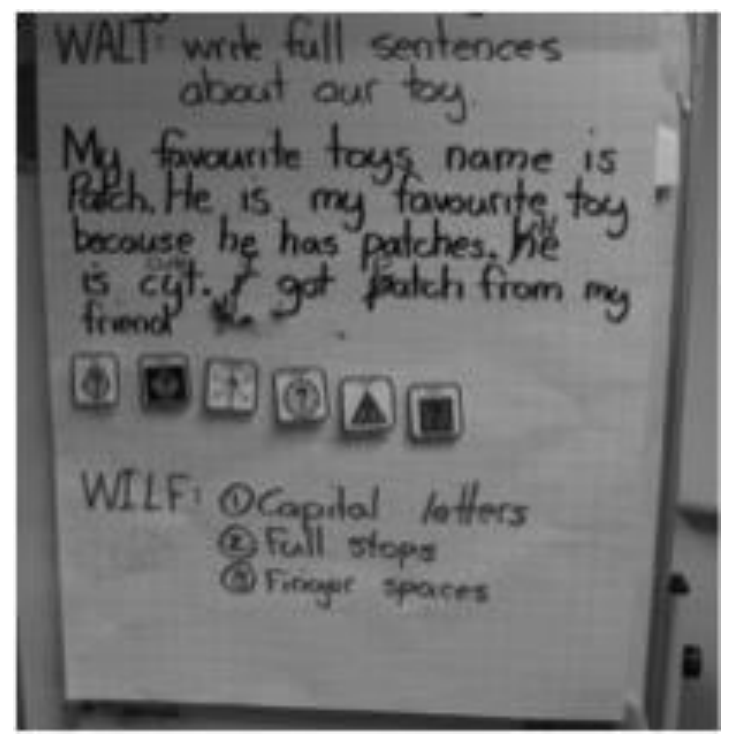

Figure 1: The schooled expectations for the task

On the top line is a WALT - an acronym that stands for 'We Are Learning To'. This indicates what the children are intended to progress towards in their acquisition of literacy skills and knowledge during the lesson. At the bottom of the sheet is the 
'WILF' - 'What I am Looking For' which stipulates what the teacher expects to find when the children's written work is reviewed. In this case, these expectations were set in accordance with the then literacy curriculum for five-year-old children in Year 1 as set down in national (English and Welsh) policy documents at the time. Thus the teacher stipulated that the writing contain 'full sentences'. This means that their sentences should be grammatically simple - that is, comprised of a single clause be demarcated with a full stops and capital letters, and have (finger) spaces between words (DfES 2006 p.24 - 25).

As well as these expectations, the teacher also modelled particular processes the children should engage in as they produced their texts and stipulated the required content. In the middle of the page in Fig.1 (beginning with the words 'My favourite toys') is a piece of writing the teacher produced with the class prior to the children's independent work on producing their own texts. During this pedagogical process the teacher emphasised the following expectations:

\section{- the use of phonics, or 'sounding out' to spell}

This was particularly stressed, with the teacher saying '...obviously you need to do your best sounding out...' before the children were sent to start writing

\section{- the use of adjectives}

For example a child was praised for saying her doll had a 'beautiful' dress

\section{- using capital letters for names}

\section{- including particular content}

The writing should include the name of the favourite toy, state why it was a favourite and where and when the children received it

These expectations focused on securing progression for children in acquiring literacy skills, in particular grammar, punctuation and spelling. These skills were directly related to expectations for the children's chronological age (DfES 2006 p.24 - 25). For example, in the curriculum structure related to spelling at the time Year 1 children were expected to 'spell new words using phonics as the prime approach' (DfES 2006 p.24). Combining this phonic knowledge with other strategies for spelling such as '...word recognition and knowledge of word structure, and spelling patterns...' (DfES 
2006 p.26) was not expected until the following year (Year 2). The intention of such a curriculum structure was to avoid introducing the youngest children in school to the full complexity of the English spelling system before they could be expected to manage it (House of Commons 2005 p.13 - 14).

From current educational perspectives, the task of the school is to ensure children move in an orderly fashion along a universal path of the acquisition of core skills and knowledge in literacy (Sealy 2000 p.81) and any deviation from this orderly acquisition is to be corrected as soon as possible (cf Walkerdine 1993). Whilst the pedagogical practices described above can be supportive of young children's writing, it can also be argued that they reflect views of young children as incompetent, ignorant and separated from, rather than part of, a society they might only become full members of as adults (cf Hendrick 1997, Wyness 2012). In her professorial lecture at the Institute of Education (University of London) in 2003, Berry Mayall summed up this perception of young children and language in education:

$$
\begin{aligned}
& \text { 'Definitions - or constructions - of children as incompetent, immature, } \\
& \text { morally suspect pupils have pervaded thinking in the education system.' }
\end{aligned}
$$

[Mayall 2003 p.20]

Mayall describes indicators of this attitude towards children:

'Testing, marking, adult supervision, adult control over the subject matter of learning, and the processes of learning are all indicators of denigration.'

[Mayall 2003 p.19-20]

In the February literacy lesson described here pedagogical practices such as those described by Mayall are evident. The children's literacy practices were tightly controlled, firstly by relating their successful participation to their progression towards age related expectations; secondly by restricting the expected content of their writing and thirdly by modelling the processes of writing that the children were expected to engage in. Thus the uses and meanings that children might hold for literacy in their current social lives as children were accorded less importance than adult concerns about what will best for them in their future participation as adults in the social world.

In the following analysis I demonstrate how these views of young children are insufficient to account for Dean's participation in process of producing a text in line 
with the expectations set for this February literacy lesson. I adopt the perspective of Literacy as a Social Practice to place Dean at the centre of the analysis; not in terms of what he does in response to adults' pedagogical interventions - such as that of the modelled writing described above - but as a literacy practitioner in his own right.

\section{Dean}

Dean was judged to be 'below average attainment' in literacy for his chronological age (5 years) and so often received support from the teacher and other adults when he engaged with schooled literacy tasks. This particular lesson was chosen because there was detailed data on Dean's participation including audio recordings, photographs and documents, as well as a post-lesson interview where I discussed Dean's experience of the literacy lesson with him. The analysis placed priority on making plausible inferences about Dean's interpretation of what he was doing in the light of the rage of ethnographic data described above. This is not to claim that such inferences can be understood as a certainty, however it is to claim the theoretical framework that informs such analysis offers greater scope for understanding Dean's literacy practices than the assumptions made within schooled discourses and practices.

\section{Dean's values, attitudes and beliefs about schooled literacy}

Dean took a positive stance towards his encounter with schooled literacy and was eager to make progress according to schooled expectations. He was a full participant in the whole class session described above. As the teacher and class produced the

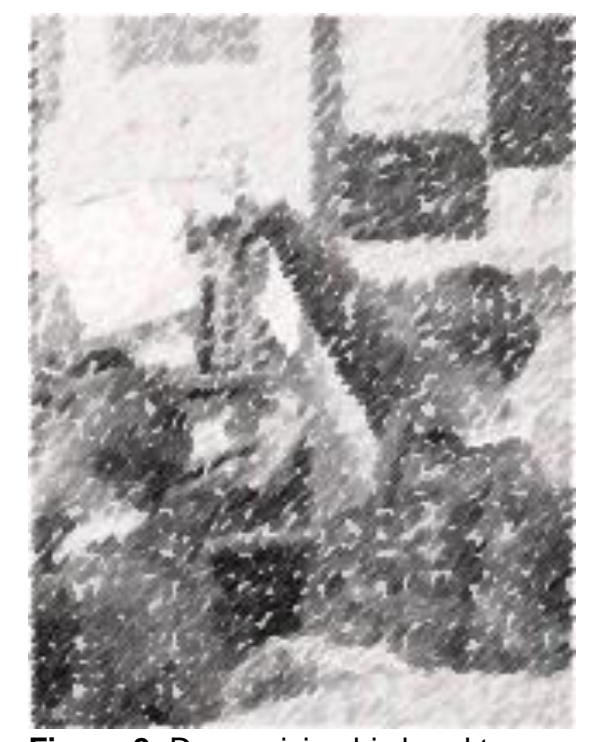

Figure 2: Dean raising his hand to participate in the shared writing part of the session 
shared writing in Fig 1, Dean participated enthusiastically, frequently raising his hand to respond to questions (Fig 2, below).

Furthermore, in an interview following the lesson, Dean showed me the work he had produced in his schooled literacy workbook, emphasising his progress. For example, when asked if he was proud of his work, Dean responded: 'Before I didn't know how to write; I used to write yuck'. When asked, he explained what made his writing 'better and better':

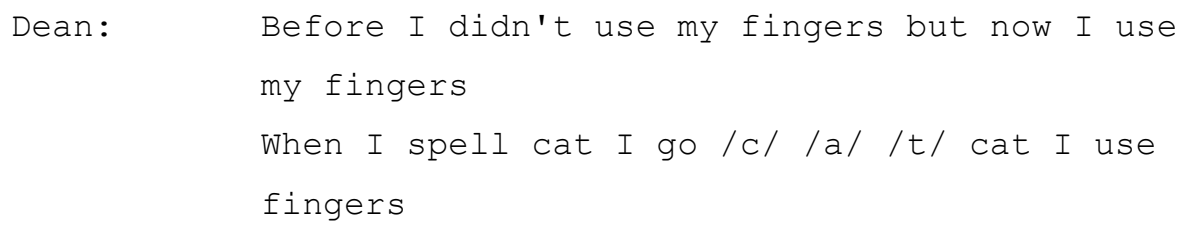

Here, 'using my fingers' relates to the practice heavily emphasised in UK policy of using phonics as the prime approach to reading and spelling (cf Rose 2006, DfE 2010), where the children use their fingers to work out how many sounds in a word they need to represent with letters. Dean was eager to make progress and understood this progress to be linked to his application of literacy skills. These values, attitudes and beliefs suggest that Dean was reproducing the literacy practises that the school expected of him and sharing schooled values.

\section{Dean's cultural reproduction}

However, despite Dean's apparent alignment with schooled expectations, there is more to his literacy practices than meets the eye. This can be exemplified by looking in detail at his process of producing the first sentence in his writing (Fig 3, below):

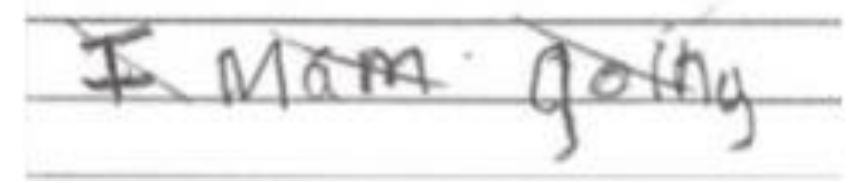

Figure 3: Dean's incomplete sentence ‘ mam (am) going

The sentence reads 'I am going' and it is part of the longer sentence 'I am going to get Pokemon for my birthday' which Dean intended to write but did not complete. His alignment with schooled values for progression and the application of literacy skills were certainly part of his practices for writing this sentence, however this does not fully account for the complexity of his engagement with the task. I shall begin describing Dean's literacy practices here, before illustrating how Corsaro's theory of 
'interpretive reproduction' offers a view of children and childhood that supports an LSP approach to understanding young children's in-class literacy practices.

\section{Interpretively reproducing literacy practices}

Throughout the writing lesson, the teacher emphasised that the children should write about their favourite toy. However, Dean's intended first sentence was about a Pokemon toy that he anticipated receiving for his birthday but did not yet possess. Thus Dean deviated from the schooled expectation for the task. This deviation reflected the current interest in Pokemon toys within Amber Class' in-class peer culture. During the shared writing session described above, the teacher had asked the children to tell her about their favourite toy. In front of the watching class, one child, Martin, told the teacher that his favourite toy was Pokemon, which could change into a dragon. This appeared to have caught the imagination of both Dean and his friend Liam. However, for Dean, this choice of subject matter posed a problem in that the schooled task required he write about a toy he already possessed. Dean resolved this tension between the interests of his in-class peer culture and the schooled expectations by deciding to write that he would receive the toy for his forthcoming birthday. He expressed this intention to his friend Liam when the two children had been sent to the tables where they would complete the individual writing task:

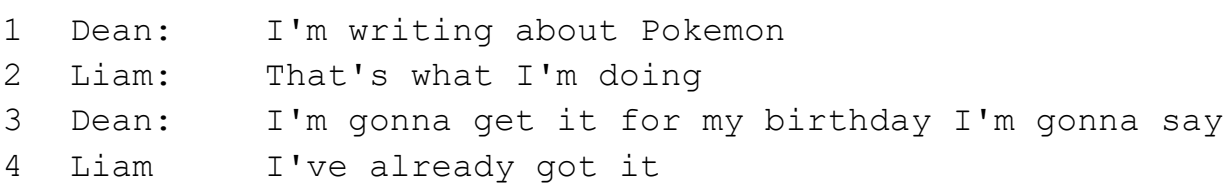

However, the problem of deviating from the school assigned task was highlighted by another child at the writing table, Sharon, who overheard Dean asking Liam for help with spelling. In the following exchange, Sharon tried to establish whether or not Dean owned the Pokemon toy that he was writing about and thus whether the topic of his writing would meet the schooled expectations:

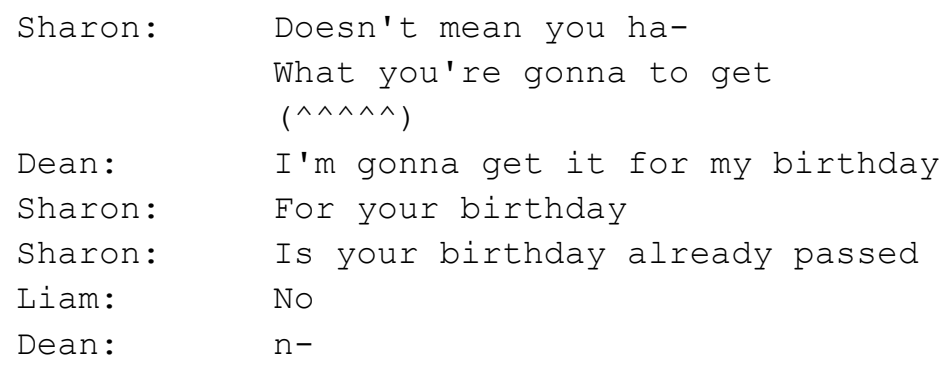


10 Sharon: Do you mean that-

11 Martha: ((addressing the class)) wow Amber Class you've really got settled

At lines 1 and 2 I believe that Sharon is referring to the set task, telling Dean it 'doesn't mean' he can write about what he's 'gonna get'. She then pursues the issue by working to clarify whether Dean has had his birthday and therefore owns the toy in question. Here, Sharon and Dean shared a belief that they were obliged to meet schooled expectations when engaging in schooled literacy tasks. This belief was embedded in Amber Class' children's in-class peer culture. For example, children were heard talking about what they 'have to', are 'supposed to' or 'allowed to 'do, sometimes intervening in each other's work, as Sharon does here, to bring it back into line with the schooled expectations. Within the peer culture it was therefore understood that schooled writing tasks constrained their writing in particular ways and the children engaged in activity that helped them to keep within such constraints. Thus Dean's assertion at line 9 in the above interaction that his birthday has passed would quell Sharon's doubts about the legitimacy of his chosen subject matter within the constraints of the school assigned task and thus secure his right to write about the desired toy.

This work to write about the Pokemon toy despite the schooled constraints on the subject matter of his writing suggests that Dean was not straightforwardly reproducing the literacy practices advocated by adults. Instead, he was creatively appropriating the opportunity afforded by the schooled task in order to negotiate a social context where schooled and peer culture concerns were both important to him. (cf Bourne 2001, 2002; Maybin 2007). Here, I return to Corsaro's theory of 'interpretive reproduction' offers scope for understanding the complex interpretive aspects of Dean's reproduction of literacy practices in this lesson.

Corsaro's theory of 'interpretive reproduction' arose from his observations of young children participating in the social world of kindergarten and elementary school classrooms in Italy and the US. Corsaro explains his theory thus:

'The term interpretive captures innovative and creative aspects of children's participation in society. Children produce and participate in their own unique peer cultures by creatively appropriating information from the adult world to address their own peer concerns. The term reproductive captures the idea 
that children are not simply internalising society and culture, but are also actively contributing to cultural production and change. The term also implies that children are, by their very participation in society, constrained by the existing social structure and by social reproduction.'

[Corsaro 2000 p.92]

This theory offers a helpful way of understanding how young children reproduce literacy practices in classroom settings. In this case, Dean innovatively and creatively participated in the social world of the classroom. Within that social world he had his own concerns, at least some of which were shared within his in-class peer culture. To address these concerns, Dean negotiated between his interest in the Pokemon toy and his belief in the desirability for meeting the expectations of schooled literacy tasks; both in his construction a suitable sentence and his defence of his choice of subject matter to Sharon. Furthermore, Dean's choice of subject matter was constrained by the existing social structure of the classroom. Whilst Dean's decision to write about receiving the Pokemon toy for his birthday arose from his current social context, it was also constrained by the dominance of schooled literacy within that context; and informed by the values, attitudes and beliefs of his in-class peerculture. Had Dean been writing in a social context outside the schooled writing lesson, he would not have had to meet the schooled obligation to write about a toy he already possessed. Lastly, Dean's engagement with the schooled literacy task in the classroom was not wholly an individual cognitive process. A great deal of Dean's work to produce his sentence involved social interactions with both the teacher's pedagogical processes and his in-class peer culture.

This analysis of Dean's work to write about the Pokemon toy demonstrates how young children's engagement with schooled literacy activities involves the reproduction of complex, context embedded social practices. Within the mainstream discourses of schooled literacy, Dean's success or otherwise as a literacy practitioner was measured in terms of his ability to individually acquire and deploy particular literacy skills in comparison with age related expectations. The evidence presented here suggests that this tight focus on universal progression in skills acquisition means that the creative, collective and problem-solving aspects of Dean's interpretive reproduction of literacy practices remain outside the scope of much mainstream educational research and practice. I argue that the work of this mainstream research and practice is not to understand what children do find helpful when engaging in literacy tasks, but to bring their literate behaviour into line with 
what adults think they ought to do. However, this schooled approach to understanding children's literacy practices offers to narrow a view of the work that children, both individually and within their in-class peer cultures, do to engage with schooled literacy tasks. To demonstrate the relative complexity and sophistication of this work, I now turn to an analysis of Dean and his friend Liam's interpretive reproduction of literacy practices to transcribe Dean's intended sentence -'I'm gonna get Pokemon for my birthday'.

\section{Dean and Liam write 'I am gonna get'}

When Dean began to transcribe his sentence, he drew on both his own literacy skills and the support of his friend Liam. This collective approach to the schooled task was an example of a wider in-class peer culture value for sharing engagement with schooled literacy tasks. There are many instances of this in the data set. For example, children would share their written texts with other children; work cooperatively on text production tasks; and often showed concern for their peers' successful completion of text production tasks. There was some support for such collaborative work within schooled practice, particularly in the layout of the classroom furniture, which allowed the children to talk to each other as they worked. However, this apparent support for collaborative work was contradicted by the schooled emphasis on assessing children's individual levels of skills and knowledge in literacy. Thus whilst collaborative work was recognised as helpful, the children's ability to make effective use of such work was not subjected to the same level of scrutiny as their individual ability to apply literacy skills. In contrast, the interpretive reproduction of literacy practices places emphasis on the importance of peer culture and collective practice, and thus allows for analysis of Dean's literacy practices that encompasses his work to engage in collective practice. Here, such an analysis of Dean's work with Liam to write 'gonna get' illustrates how relatively sophisticated and complex such processes can be.

It is important to note that Dean's decision to draw on Liam's expertise did not reflect a dependence on Liam's support. When Dean began transcribing his sentence he wrote the first two words without help from Liam. The audio recording suggests he wrote ' $l$ ' from memory and drew on the school-emphasised process of using phonics for 'am'. Once he reached the word 'gonna' however he requested help from Liam. This suggests that Dean was aware that particular aspects of literacy were beyond his current expertise and this awareness informed decisions about when to draw on the expertise of others. Furthermore, the following analysis of the children's 
interaction as they worked together to spell 'gonna get' suggests that this sharing of expertise involved an interactional process that was carefully managed by both children.

The transcription below begins as Liam starts to support Dean in spelling. For clarity, I note that whilst Dean requested help to spell 'gonna get', Liam began to support him in a more 'Standard English' spelling of 'going to get':

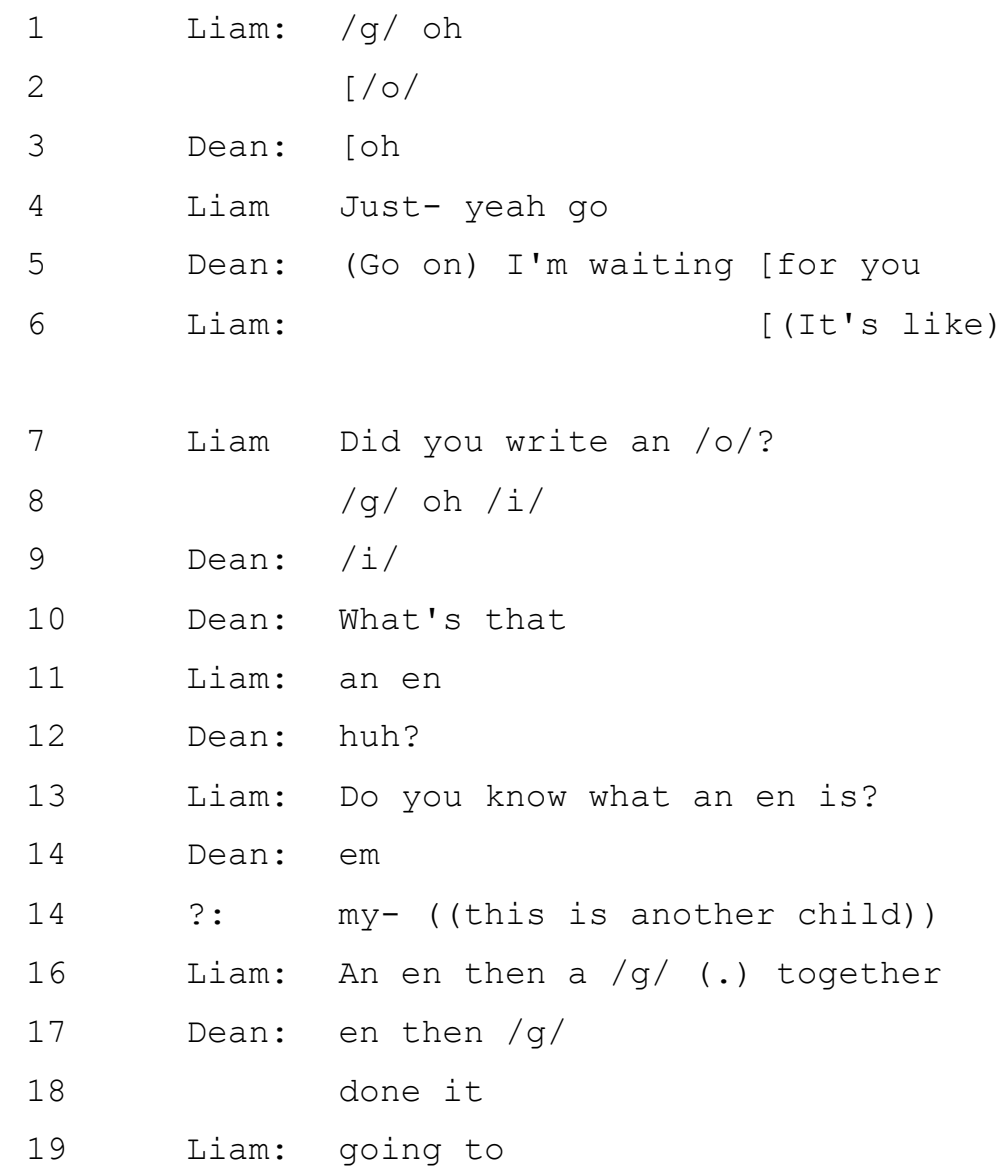

Liam began by spelling out the word 'going' as requested by Dean (1). As Dean wrote the word, Liam summarised what had been spelt so far (4). Dean prompted Liam when he was ready for support with the next word (5) and Liam checked what Dean had done (7) before adding the next letter /i/ (8). Dean then queried one of Liam's suggestions (10) and Liam clarified what the problem might be (13). Following this, Liam gave explicit instructions about the final two letters (16); Dean announced he had completed the word (18); and Liam situated what Dean had written so far 'going' - in the context of what they would write next - 'to' (19). In this instance, the children's work to spell 'going to get' demonstrates how they both managed sharing 
expertise as a resource through relatively complex spoken interactions involving: summarising (4); checking progress (7); clarifying points of confusion (10) - (13); and contextualising the work in progress (19). Within this complex process, both children drew on 'literacy skills' promoted within schooled literacy - both children used their knowledge of written letters and Liam used his knowledge of Standard English written forms to support Dean's sentence writing. However, this was situated within a wider social process of the interpretive reproduction of literacy practices involving: a) the in-class peer culture value for practising literacy collectively; b) both children's management of this collective practice through spoken interaction; and c) the children's active and collaborative reproduction of schooled literacy skills.

This process demonstrates that, whilst the application of literacy skills is an important part of young children's in-class literacy practices, it certainly does not fully capture the complex social processes illustrated above. For example, whilst the data shows Dean's value for, and successful application of, phonics for spelling, this is only a small part of what he does when he practises literacy in the classroom. Barton (2007) suggests that it is helpful '...to see skills as situated within practices...' (Barton 2007 p.163; see also Purcell-Gates, Jacobson and Degener 2004 ), and that certainly seems to be the case here. However, the schooled assessment and teaching practices that Dean and Liam were subject to in school focus on the tight measurement and control of their acquisition and application of literacy skills. I suggest that the application of the aligned perspective of Literacy as a Social Practice and 'interpretive reproduction' (Corsaro 2005, 2011, 2015) allow for the situation of these valued skills within wider social practices that include:

- children's active and creative work, often within their local peer culture, to make sense of the social world.

- children's values, attitudes and beliefs about literacy and the social context in which they are required to practice it

- the key role of social interaction

- collective as well as individual reproduction of literacy practices

- the role of young children's in-class peer cultures in their in-school literacy acquisition 
In the analysis above, each of these factors played a part in understanding Dean's engagement with the task of writing about his favourite toy. I suggest that such an analysis has the potential to support more careful assessments of young children's development of literacy practices and thus the design of teaching approaches that are more closely aligned to children's needs.

\section{Discussion}

Mainstream educational concerns of individual 'attainment' and 'progress' in the acquisition of literacy skills dominate the ways in which young children's in-school literacy practices are understood by adults in schools. Whilst such concerns can and do contribute to the work of schools to support young children's acquisition of literacy, they can also constrain practitioners within overly narrow views of children's engagement with school assigned literacy tasks in the context of the classroom. As MacLure suggests:

'Perhaps the most intransigent problem, for educators and researchers alike, is the strength of received notions of 'the child'.'

[MacLure 2012, p.467]

An example of this is the perceived need for young children's early literacy practices to be closely supervised by adults to avoid misunderstandings and misconceptions arising from their 'immaturity' or 'incompetence' (Mayall 2003, above). To return briefly to Dean, I note that the sentence 'I am gonna' has been crossed out in his writing (Fig. 3). On discovering what Dean was writing, the teacher began the task with him again, producing the sentence 'My favourite toy is Pokemon,' which aligned with schooled expectations. This is not to suggest that the teacher's actions as an individual were 'wrong', rather it is to say that the discourses of young children and literacy within which class teachers' in England work emphasise the importance of keeping children's literacy practices within schooled expectations for engagement with the tasks set. This can mean that deviations from such expectations are considered as mistakes or misunderstandings, when this data suggests that they may arise from complex, meaningful social practices. This is not to say that Dean does not require support in developing his literacy skills. Indeed, Dean is aware of this need himself and seeks out Liam's support as required. However it is to say that powerful, schooled discourses of young children and literacy potentially limit the capacity of educators to fully understand the complex social practices, and the role of 
the children's in-class peer cultures, in which the acquisition and application of literacy skills are located.

For example, the current schooled focus in England and beyond (cf Dyson 2010) remains on children's individual acquisition and application of literacy skills often through adult dominated activities. However, Dean's spelling of 'gonna get' is dependent on his positive social relations with Liam and their relatively sophisticated social interaction within an in-class peer culture that values collective engagement with schooled literacy tasks. It is thus plausible to argue that young children's development of literacy practices may be well supported by work to support the collective reproduction of such practices. Similar examples of collective practice have been observed by other authors studying children's in-school literacy practices in both the UK and the US. Dyson (1987) used the concept of interpretive reproduction in a study of 7 - 8 year old children's 'unintentional helping' of each other within official and unofficial literacy activities in US schools (Dyson 1987). This work stressed the importance of young children's peer cultures in their engagement with schooled literacy (Dyson 1987 p.23 - 24). In particular, Dyson described children instructing each other in literacy in schooled spaces which allow peer group collaboration to flourish. She found that '...the children were providing for themselves much more sophisticated lessons than adults could ever hope to.' (Dyson 1987 p.24) In more recent UK research, Chen and Gregory (2004), describe how two Cantonese speaking Primary school pupils, aged 7 and 9, worked together on a schooled literacy task. One child supplied proficiency in English and the other controlled the way that proficiency was shared between them (Chen and Gregory 2004 p.127). Similarly Datta (2004) describes how two groups of children '...support each other's language and literacy learning through their friendship.' (Datta 2004 p.140). Thus, within children's peer cultures, literacy can be a collective accomplishment achieved through complex social interaction involving drawing on relative expertise as a shared resource.

However whilst schools ostensibly provide opportunities for such collaborative practice, this is contradicted by procedures and practices which emphasise individual attainment. For example, in Amber Class children's individual workbooks were marked in relation to the children's individual deployment of literacy skills and children's competence in writing was regularly assessed under 'test' conditions which included the requirement for the children to work silently. A concern here is that, as children proceed through school, this valuable aspect of the interpretive reproduction 
of literacy practices remains unsupported and potentially underdeveloped. For example, evidence from my interview with Dean following the lesson described above suggests that he understood that collective practices of literacy were not desirable in school. Firstly, Dean's hesitant response to my enquiry about his work with Liam contrasted with his earlier confident discussion about the writing in his workbook. Dean responded to my question by saying Liam helped him 'Just a little bit' and stressing 'we (the children) write by ourselves'. He then emphasised the limits of Liam's support, saying that Liam only helped him with 'gonna get' because 'that's a hard word and that's it...' Secondly, Dean seemed to understand that talking with his friends was not approved of in school. During the lesson, the teacher called Dean to another table. When I asked Dean why this was he responded it was because he and Liam had been naughty. When asked what being naughty meant he said 'We talk, just that, we talk.' This suggests that Dean's interpretation of schooled expectations for his literacy practices included a perception that talking was 'naughty'. This is not to suggest that collaboration was not valued by the adults in the classroom, rather that features of the social context of the classroom may lead children to perceive that this was the case. Thus whilst Amber Class children valued and engaged in social interactions as an important part of their peer-culture practices of literacy, Dean at least understood that this was not valued in school.

\section{Conclusion}

This article has focused on one child's engagement with a schooled literacy task in order to argue that the assumptions upon which current English literacy education policy rests are insufficient to account for the complexity of young children's in-school practices of literacy. I argue that the task for policy makers and researchers is to develop robust conceptual frameworks for understanding what young children actually do when they practice literacy in schooled contexts, rather than comparing them to what adults think they ought to do. The analysis in this article has shown how Dean's interpretive reproduction of literacy practices could be a collective accomplishment, dependent on social interaction; grounded in the values and interests of a shared and stable in-class peer culture; and arising from the his own and his peers' interpretations of the schooled context. However, current schooled perspectives on young children's literacy development focus on their orderly acquisition of literacy skills, in particular young children's use of phonics for reading and spelling (cf DfE 2014). This data suggests that such skills are situated in wider social processes which are not sufficiently understood within current English schooled assumptions about young children's early in-school literacy development. 
This article has focused on Dean's unfolding in-class literacy practices, however it should be remembered that researchers have explored the diversity of literacy practices in homes and communities beyond the classroom (cf Gregory 1996, 1997; Gregory and Williams 2000; studies in Gregory, Long and Volk 2004; Gregory, Williams, Baker and Street 2004). Such out-of-school literacy practices can also be drawn into young children's interpretive reproduction of in-school literacy practices (cf Dyson 1999, 2003). Research such as this demonstrates that the diversity and complexity of young children's literacy practices are not sufficiently understood within schooled discourses that focus on children's acquisition and application of literacy skills. The challenge for policy makers and teachers is therefore to understand and work effectively with the diverse and complex literacy practices that young children interpretively reproduce in the classroom.

\section{References}

Andrews, J., Robinson, D. \& Hutchinson, J. 2017, Closing the Gap? Trends in educational attainment and disadvantage, Education Policy Institute, https://epi.org.uk/wpcontent/uploads/2017/08/Closing-the-Gap EPI.pdf.

Ball, S. 1993, "What is Policy? Texts, Trajectories and Toolboxes", Discourse, vol. 23, no. 3 , pp. 257-274.

Barton, D. 2007, Literacy: An Introduction to the ecology of written language, Second edn, Blackwell, Oxford.

Barton, D. \& Hamilton, M. 1998, Local Literacies: Reading and writing in one community, Routledge, London.

Barton, D. \& Hamilton, M. 2000, "Literacy Practices" in Situated Literacies: Reading and Writing in Context, eds. D. Barton, M. Hamilton \& R. Ivanic (eds) Routledge, London, pp. 7-15.

Barton, D., Hamilton, M. \& Ivanic, R. (eds) 2000, Situated Literacies: Reading and Writing in Context, Routledge, London.

Blommaert, J. \& Jie, D. 2010, Ethnographic Fieldwork: A beginner's guide, Multilingual Matters, Bristol.

Bourne, J. 2002, "Oh, What Will Miss Say!: Constructing texts and identities in the discursive process of classroom writing.", Language and Education, vol. 16, no. 2, pp. 241-259.

Bourne, J. 2001, "Discourses and Identities in a Multi-lingual Primary Classroom", Oxford Review of Education, vol. 27, no. 1, pp. 103-114.

Chen, Y. \& Gregory, E. 2004, "'How Do I Read These Words?': Bilingual exchange teaching between Cantonese speaking peers" in Many Pathways to Literacy: Young children learning with siblings, grandparents, peers and communiites, eds. E. Gregory, S. Long \& D. Volk, Routledge Falmer, London, pp. 117-128. 
Corsaro, W. 2015, The Sociology of Childhood, Fourth edn, Sage, London.

Corsaro, W. 2011, The Sociology of Childhood, Third edn, Sage, London.

Corsaro, W. 2005, The Sociology of Childhood, Second edn, Sage, London.

Corsaro, W. \& Nelson, E. 2003, "Children's Collective Activities and Peer Culture in Early Literacy in American and Italian Pre Schools", Sociology of Education, vol. 76, no. 3, pp. 209-227.

Corsaro, W. 2000, "Early Childhood Education, Children's Peer Cultures and the Future of Childhood", European Early Childhood Education Research Journal, vol. 8, no. 2, pp. 89-102.

Corsaro, W. \& Molinari, L. 2000, "Priming Events and Italian Children's Transition from Preschool to Elementary School: Representation and Action", Social Psychology Quarterly, vol. 63, no. 1, pp. 16-33.

Datta, M. 2004, "Friendship Literacy: Young children as cultural and linguistic experts" in Many Pathways to Literacy: Young children learning with siblings, grandparents, peers and communiites, eds. E. Gregory, S. Long \& D. Volk, Routledge Falmer, London, pp. 129-141.

DfES: 2006, Primary Framework for Literacy and Mathematics, DfES.

DfE 2014, 16th July 2014-last update, English Programmes of Study: key stages 1 and 2; National Curriculum in England. Available:

https://www.gov.uk/government/uploads/system/uploads/attachment_data/file/3351 86/PRIMARY national curriculum - English 220714.pdf [2016, April].

Dyson, A. 2010, "Writing Childhoods Under Construction: Re-visioning 'copying' in early childhood", Journal of Early Childhood Literacy, vol. 10, no. 1, pp. 7-31.

Dyson, A. 2006, "On Saying it Right (Write): "Fix-its" in the foundations of learning to write", Research in the Teaching of English, vol. 41, no. 1, pp. 8-42.

Dyson, A., 2003. 'Welcome to the Jam': Popular culture, school literacy, and the making of childhoods. Harvard Educational Review, vol. 73, no. 3, pp. 328-361.

Dyson, A. 2001, "Where are the Childhoods in Early Childhood Literacy? An exploration in outer (school) space", Journal of Early Childhood Literacy, vol. 1, no. 9, pp. 9-39.

Dyson, A., 1999. Coach Bombay's Kids learn to Write: Children's appropriation of media material for school literacy. Research in the Teaching of English, vol. 33, no. 4, pp. 367402.

Dyson, A. 1987, Unintentional Helping in the Primary Grades: Writing in the children's world, Center for the Study of Writing: University of California, Berkley Carnegie Mellon University, Berkley, California.

Flewitt, R. 2011, "Bringing Ethnography to a Multimodal Investigation of Early Literacy in a Digital Age", Qualitative Research, vol. 11, no. 3, pp. 293-310.

Gibb, N. 2017, Reading is the Key to Unlocking Human Potential.

Gove, M. 2010, Michael Gove to Westminster Academy, https://www.gov.uk/government/speeches/michael-gove-to-westminster-academy. 
Gregory, E. (ed) 1997, One Child, Many Worlds: Early learning in mulitcutural communities, David Fulton, London.

Gregory, E. 1996, Making Sense of a New World: Learning to read in a second language, Paul Chapman, London.

Gregory, E., Long, S. \& Volk, D. (eds) 2004, Many Pathways to Literacy: Young children learning with siblings, grandparents, peers and communiites, RoutledgeFalmer, London.

Gregory, E. \& Williams, A. 2000, City Literacies: Learning to read across generations and cultures, Routledge, London.

Gregory, E., Williams, A., Baker, D. \& Street, B. 2004, "Introducing Literacy to Four Year Olds: Creating Classroom Cultures in Three Schools", Journal of Early Childhood Literacy, vol. 4, no. 1, pp. 85-107.

Hammersley, M. \& Atkinson, P. 2007, Ethnography: Principles in practice, 3rd edn, Routledge, London.

Heath, S.B. 1983, Ways with Words: Language, life and work in communities and classrooms, Cambridge University Press, Cambridge.

Heath, S.B. \& Street, B. 2008, Ethnography: Approaches to language and literacy research, Teachers' College Press, New York.

Hendrick, H. 1997, "Constructions and Reconstructions of British Childhood: An interpretive survey, 1800 to the present" in Constructing and Reconstructing Childhood, eds. A. James \& A. Prout, Falmer Press, London, pp. 34-62.

House of Commons Education and Skills Committee 2005, Teaching Children to Read, The Stationery Office, London.

Jewitt, C. March 2012, "An Introduction to Using Video for Research", National Centre for Research Methods Working Papers, [Online], . Available from: http://eprints.ncrm.ac.uk/2259/.

McGrane, J., Stiff, J., Baird, J., Lenkeit, J. \& Hopfenbeck, T. 2017, Progress in International Reading Literacy Study (PIRLS): National Report for England, OUCEA, Department of Education, University of Oxford.

MacLure, M., Jones, L., Holmes, R. \& MacRae, C. 2012, "Becoming a Problem: behaviour and reputation in the early years classroom", British Educational Research Journal, vol. 38, no. 3, pp. 447-471.

Mayall, B. 2003, Sociologies of Chldhood and Educational Thinking: professorial lecture, Institute of Education, University of London, London.

Maybin, J. 2013, "What Counts as Reading? PIRLS, EastEnders and The Man on the Flying Trapeze", Literacy, vol. 47, no. 2, pp. 59-66.

Maybin, J. 2007, "Literacy Under and Over the Desk: Oppositions and Heterogeneity", Language and Education, vol. 21, no. 6, pp. 515-530.

OECD 2016, Pisa 2015 Results (Volume 1): Excellence and Equity in Education, OECD Publishing, Paris. 
OFSTED 2010, Reading by Six: How the best schools do it, The Office for Standards in Education, Children's Services and Skills, Manchester.

Papen, U. 2016, Literacy and Education: Policy, Practice and Public Opinion, Routledge, Abingdon.

Purcell-Gates, V., Jacobson, J. \& Degener, S. 2004, Print Literacy Development: Uniting Cognitive and Social Practice theories, Harvard University Press, Harvard.

Rampton, B. 2007, "The micro-analysis of interactional discourse in linguistic ethnography: An illustration focused on the job interview", Key Concepts and Methods in Ethnography, Language and Communication.

Rampton, B. 2006, Language in Late Modernity: Interaction in an urban school, Cambridge University Press, Cambridge.

Rose, J. 2006, Independent Review of the Teaching of Early Reading, DfES Publications, London.

Sealy, A. 2000, Childly Language: Children, language and the social world, Pearson Education, Essex.

Standards and Testing Agency 2015, Interim Teacher Assessment Frameworksat the end of Key Stage 1, Gov.UK, www.gov.uk.

Street, B. 1984, Literacy in Theory and Practice, Cambridge University Press, Cambridge.

Street, B. \& Street, J. 1995, "The Schooling of Literacy" in Social Literacies: Critical Approaches to Literacy in Development, Ethnography and Education, ed. B. Street, pp. 106-131.

Walkerdine, V. 1993, "Beyong Developmentalism?", Theory and Psychology, vol. 3, no. 4, pp. 451-469.

Wyness, M. 2012, Childhood and Society, 2nd edn, Palgrave Macmillan, Basingstoke.

\section{Acknowledgements}

With thanks to Sarah Leonard; Marie-Pierre Moreau; Sarah O'Flynn and Vini Lander for their generous support in the preparation of this manuscript. I am especially grateful to Roxy Harris and Brian Street for their support throughout the PhD study upon which this manuscript draws. 